\title{
Emergence of plasmid-mediated mcr genes from Gram-negative bacteria at the human-animal interface
}

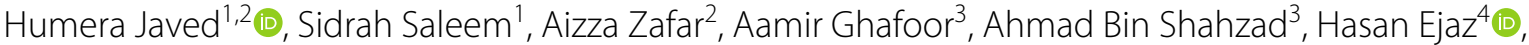 \\ Kashaf Junaid ${ }^{4}$ (D) and Shah Jahan ${ }^{5 *}$ (1)
}

\begin{abstract}
Background: The global emergence of plasmid-mediated colistin resistance (Col-R) conferred by mcr genes in gramnegative rods (GNRs) has jeopardized the last treatment option for multidrug-resistant bacterial infections in humans. This study aimed to assess the emergence of mcr gene-mediated Col-R in GNRs isolated from humans and animals in Pakistan.
\end{abstract}

Methods: Animal and clinical specimens collected from various sources were prospectively analysed using standard microbiological procedures. Pathogens were identified using the API 20E and API 20NE systems (bioMerieux). Minimum inhibitory concentration (MIC) against colistin was determined using the MIC detection methods, and multiplex polymerase chain reaction (PCR) was used to amplify the mcr-1 to mcr-5 genes.

Results: We isolated 126 (88.1\%) animal and 17 (11.9\%) human Col-R phenotypes, among which there was a significant association ( $P<0.01)$ of Escherichia coli and Proteus mirabilis with animals and of Acinetobacter baumannii with humans. Animal strains exhibited statistically significant $(P<0.05)$ resistance to co-trimoxazole, chloramphenicol, and moxifloxacin, and the human pathogens exhibited statistically significant $(P<0.05)$ antibiotic resistance to cephalosporins, carbapenems, and piperacillin-tazobactam. For Col-R strains, $\mathrm{MIC}_{50}$ values were $>6 \mu \mathrm{g} / \mathrm{mL}$ and $>12 \mu \mathrm{g} / \mathrm{mL}$ for human and animal isolates, respectively. mcr genes were detected in 110 (76.9\%) bacterial strains, of which 108 (98.2\%) were $\mathrm{mcr}-1$ and 2 (1.8\%) were $\mathrm{mcr}-2$.

Conclusions: The detection of a considerable number of mcr-1 and mcr-2 genes in animals is worrisome, as they are now being detected in clinical pathogens. The acquisition of $m c r$ genes by colistin-susceptible bacteria could leave us in a post-antibiotic era.

Keywords: Antibacterial profile, Antimicrobial resistance, Colistin resistance, mcr genes, Mobile colistin resistance, Plasmid-mediated resistance

\section{Background}

Continuously emerging antibiotic resistance poses a serious survival challenge to humankind and is leading us into a post-antibiotic era. The emergence of superbugs

*Correspondence: shahjahan@uhs.edu.pk

${ }^{5}$ Department of Immunology, University of Health Sciences, Khayaban-eJamia Punjab, 54600 Lahore, Pakistan

Full list of author information is available at the end of the article carrying extended-spectrum beta-lactamases (ESBLs), AmpC beta-lactamases, and metallo-beta-lactamases has reduced therapeutic choices [1]. Colistin is a cyclopeptide antibiotic prescribed as a last resort for the treatment of extensively drug-resistant (XDR) bacteria [2]. This drug was discovered more than seven decades ago and was first introduced in the 1960s for clinical use. It was replaced with other antibiotics in the 1970s because 
of its nephrotoxic and neurotoxic effects. Since then, it has been introduced into veterinary medicine [3]. Colistin attracted renewed attention and was reintroduced as an emergency solution in the 1990s in response to the escalating prevalence of XDR bacteria [4].

The situation became alarming because of the emergence of mobile colistin resistance ( $\mathrm{mcr}$ ) genes, initially in China, in animals and humans [5]. To date, more than 40 countries have reported $m c r$ variants ( $m c r-1$ to $m c r-9$ ) from five different continents across the globe, indicating the epidemicity of the $\mathrm{mcr}$ gene [6]. The $\mathrm{mcr}$ genes have been reported in seven Asian and nine European countries, and they were recently identified in Pakistan, Iran, Italy, Finland, America, South Africa, and some other territories [7-10]. The plasmid-borne $\mathrm{mcr}$ gene has been found in several enterobacteria, including Escherichia coli, Salmonella, Aeromonas, Enterobacter cloacae, Klebsiella pneumoniae, Escherichia fergusonii, Kluyvera ascorbata, Citrobacter braakii, Cronobacter sakazakii, Klebsiella aerogenes, and, most recently, Raoultella ornithinolytica [6].

Poultry and livestock, including chickens, ducks, pigeons, geese, pigs, and cattle, have been reported to be reservoir hosts for mcr-harbouring bacterial strains [11]. Of particular note, the animal-to-human transmission of $m c r-1$ colistin resistance (Col-R) has already been established in China, Thailand, Laos, and Denmark, which has raised a serious concern about its possible global dissemination $[5,12,13]$. In addition to their isolation from animals and humans, $m c r$ genes have also been reported in bacteria from sewage, seawater, fresh food products, and seafood [14].

The extensive veterinary use of colistin and the increasing reports of Col- $\mathrm{R}$ in food animal strains of enterobacteria are indeed a matter of concern. The large-scale subclinical use of colistin for prophylaxis and growth promotion in livestock is a major cause of resistance [6]. The expansion of Col- $\mathrm{R}$ to various countries has led us to evaluate the magnitude of this drug resistance phenomenon in Pakistan. In this study, we aimed to assess the plasmid-mediated Col-R conferred by $\mathrm{mcr}$ genes among gram-negative rods (GNRs) isolated from humans and animals. The resistance spectrum of the Col- $R$ and multidrug-resistant GNRs to a variety of antibiotics was elucidated to identify possible therapeutic regimens for combating these superbugs.

\section{Methods}

\section{Study design and setting}

The study was conducted prospectively over 18 months according to the ethical principles provided by the World Medical Association (WMA) Declaration of Helsinki. The study collaborated with and received ethics approval from the University of Health Sciences and the Children's Hospital and the Institute of Child Health, Lahore, Pakistan.

\section{Sample collection}

A total of 38,500 human clinical specimens were randomly collected from the tertiary care public and private hospitals in Lahore, which treat patients from all over the Punjab province (population of approximately 120 million). The specimens collected from the clinical settings included blood, cerebrospinal fluid, swabs, tracheal secretions, urine, and faeces. Animal meat, chicken fae$\mathrm{cal}$, and respiratory secretion specimens $(n=630)$ were collected from different retail shops. We also collaborated with the University Diagnostic Laboratory (UDL), University of Veterinary and Animal Sciences, Lahore, Pakistan, to collect bacterial strains. UDL analyses animal pathological samples from all over the province.

\section{Microbiological identification}

The clinical specimens from sterile sites were processed for culture using blood, chocolate, and MacConkey's culture media [15]. Urine samples were cultured on cysteine lactose electrolyte deficient (CLED) media, while xylose lysine deoxycholate (XLD) agar was used to culture the faecal specimens. The samples collected from the animal sources were processed on XLD and MacConkey's agar. The bacterial cultures were identified using standard microbiological techniques, including Gram staining, oxidase production, and the API 20E and API 20NE systems (bioMerieux, France). Only GNRs resistant to colistin were included and processed further in our study.

\section{Minimum inhibitory concentrations (MICs) against colistin} The GNRs recovered from both human and animal sources were tested for Col-R using E-test strips (Liofilchem, Italy), and the selected strains were confirmed with the SensiTest ${ }^{\mathrm{TM}}$ Colistin (Liofilchem, Italy). Only the Col-R strains were included in the study for further processing. The minimum inhibitory concentrations (MICs) were determined using an MIC epidemiological cut-off value $(\mathrm{ECV}) \leq 2 \mu \mathrm{g} / \mathrm{mL}$ for the wild-type (WT) strains and $\geq 4 \mu \mathrm{g} / \mathrm{mL}$ for the non-wild-type (NWT) strains [16]. In the culture media and disc diffusion techniques, the ATCC 25922 (colistin-sensitive E. coli) and ATCC 25933 (colistin-resistant Proteus mirabilis) strains were used for quality control (QC).

\section{Disc diffusion antibiotic testing}

The Col-R phenotypes were assessed further to determine the association with drug resistance in the human and animal strains [16]. Antibacterial drug resistance against 16 other drugs that belong to several classes of 
antibiotics was tested using the disc diffusion method $[16,17]$. The discs primarily used included aminoglycosides, cephalosporins, fluoroquinolones, carbapenems, and beta-lactam combinations.

\section{Molecular detection of mcr genes and data analysis}

The bacterial DNA from the freshly cultured GNR strains was thermally extracted by emulsifying 2-3 colonies in $200 \mu \mathrm{L}$ of Tris EDTA (TE) buffer and boiling for $10 \mathrm{~min}$ [18]. Previously described mor 1 to $m c r 5$ primers were used in the multiplex polymerase chain reaction (PCR) [19]. The amplification was performed on a thermal cycler (Biorad, T1000) using 12.5 $\mu \mathrm{L}$ Dream Taq master mix (Thermo Fisher Scientific, USA), $0.5 \mu \mathrm{L}$ each of the 10 forward and reverse primers $(10 \mu \mathrm{M}), 5.5 \mu \mathrm{L}$ nucleasefree water, and $2 \mu \mathrm{L}$ of bacterial DNA in a final reaction mixture of $25 \mu \mathrm{L}$. The amplification procedure comprised an initial denaturation step at $94{ }^{\circ} \mathrm{C}$ for 15 min followed by 25 cycles at $94{ }^{\circ} \mathrm{C}$ for $30 \mathrm{~s}, 58^{\circ} \mathrm{C}$ for $90 \mathrm{~s}, 72^{\circ} \mathrm{C}$ for $60 \mathrm{~s}$, and a final extension at $72{ }^{\circ} \mathrm{C}$ for $10 \mathrm{~min}$ [19]. The amplified $m c r$ gene products were loaded on a horizontal agarose gel electrophoresis apparatus using $6 \times$ loading dye and SYBR ${ }^{\mathrm{TM}}$ Safe DNA gel stain (Invitrogen). A $100 \mathrm{bp}$ ladder was included with each electrophoresis run, and the gene bands were visualized with a gel documentation system (EZ Imager Bio-Rad). GraphPad Prism 7 and SPSS 23 were used for the statistical analysis. Chi-square tests were used to examine the association of antimicrobial drug-resistant microorganisms with the animal and human sources, and a significance threshold was set at $\mathrm{P}<0.05$.

\section{Results}

Association of Col-R in human and animal isolates

A total of 5,893 (15.3\%) gram-negative rods from 38,500 human clinical specimens and 630 (49\%) from 1,285 animal samples were identified. The distribution of colistin-sensitive (Col-S) and Col-R gram-negative strains isolated from human and animal sources is given in Table 1. We identified 143 gram-negative Col-R phenotypes from the human and animal isolates, of which 126 (88.1\%) were isolated from animal and 17 (11.9\%) from human sources. Among the animal isolates, 91 (72.2\%) E. coli and $20(15.9 \%)$ P. mirabilis strains were significantly associated $(\mathrm{P}<0.01)$ with the animal sources, while 3 (17.6\%) Acinetobacter baumannii strains were significantly associated $(\mathrm{P}<0.01)$ with the human sources. There was no significant association of $K$. pneumoniae and Pseudomonas aeruginosa with any source (Table 2).

\section{Distribution of Col-R strains from different specimens}

The Col-R bacterial strains were predominantly found in different poultry specimens, including 90 (62.9\%) in

Table 2 Association of colistin resistance (Col-R) in bacteria isolated from human and animal sources ( $n=143)$

\begin{tabular}{lllr}
\hline Organism & $\begin{array}{l}\text { Col-R animal } \\
\text { source } \mathbf{n}(\%) \\
\mathbf{1 2 6}(\mathbf{8 8 . 1 )}\end{array}$ & $\begin{array}{l}\text { Col-R human } \\
\text { source } \mathbf{n}(\%)\end{array}$ & P-value \\
\hline 17 (11.9) & \\
\hline K. coli & $91(72.2)$ & $3(17.6)$ & $<0.01$ \\
P. aeruginosa & $3(2.4)$ & $1(5.9)$ & 0.62 \\
A. baumannii & $0(0)$ & $0(0)$ & 0.52 \\
P. mirabilis & $20(15.9)$ & $3(17.6)$ & $<0.01$ \\
\hline
\end{tabular}

Table 1 Distribution of colistin-sensitive (Col-S) and colistin-resistant (Col-R) gram-negative strains isolated from human and animal sources

\begin{tabular}{|c|c|c|c|c|c|c|}
\hline \multirow[t]{2}{*}{ Organisms } & \multicolumn{3}{|c|}{ Animal isolates $(n=1285)$} & \multicolumn{3}{|c|}{ Human isolates $(n=5893)$} \\
\hline & Total & Col-S & Col-R & Total & Col-S & Col-R \\
\hline E. coli & 658 & $567(86.2 \%)$ & 91 (13.8\%) & 2219 & 2216 (99.9\%) & $3(0.1 \%)$ \\
\hline Klebsiella species & 231 & $219(94.8 \%)$ & $12(5.2 \%)$ & 1592 & $1591(99.9 \%)$ & $1(0.1 \%)$ \\
\hline Pseudomonas species & 81 & $78(96.3 \%)$ & $3(3.7 \%)$ & 995 & $995(100 \%)$ & $0(0 \%)$ \\
\hline Citrobacter species & 89 & $89(100 \%)$ & $0(0 \%)$ & 351 & $351(100 \%)$ & $0(0 \%)$ \\
\hline Acinetobacter species & 0 & $0(0 \%)$ & $0(0 \%)$ & 318 & $315(99.1 \%)$ & $3(0.9 \%)$ \\
\hline Enterobacter species & 85 & $85(100 \%)$ & $0(0 \%)$ & 260 & $260(100 \%)$ & $0(0 \%)$ \\
\hline Proteus species & 20 & $0(0 \%)$ & $20(100 \%)$ & 10 & $0(0 \%)$ & $10(100 \%)$ \\
\hline Salmonella species & 109 & $109(100 \%)$ & $0(0 \%)$ & 85 & $85(100 \%)$ & $0(0 \%)$ \\
\hline Sphingomonas paucimobilis & 0 & $0(0 \%)$ & $0(0 \%)$ & 25 & $25(100 \%)$ & $0(0 \%)$ \\
\hline Chryseomonas luteola & 4 & $4(100 \%)$ & $0(0 \%)$ & 19 & $19(100 \%)$ & $0(0 \%)$ \\
\hline Pantoea species & 8 & $8(100 \%)$ & $0(0 \%)$ & 19 & $19(100 \%)$ & $0(0 \%)$ \\
\hline
\end{tabular}


faecal, $22(15.4 \%)$ in meat, and $14(9.8 \%)$ in secretion samples. From the human sources, 6 (4.2\%) Col-R strains were found in urine, and 5 (3.5\%) were found in tracheal

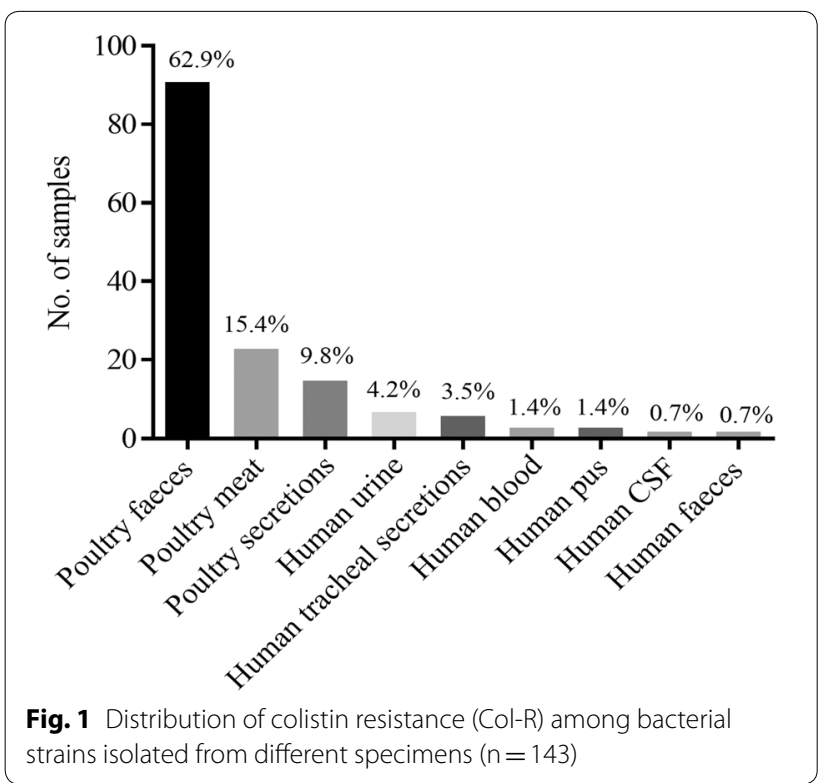

secretions, while the rest of the strains were found in the other human specimens (Fig. 1). The predominant source was poultry faeces, with 70 samples $(77.8 \%)$ containing E. coli and 16 (17.8\%) containing P. mirabilis, followed by poultry meat, with 18 samples $(81.1 \%)$ containing E. coli. The frequencies of bacterial isolates from each animal source are shown in Fig. 2.

\section{Drug-resistance spectrum against various antibiotics}

For the animal strains, there was a statistically significant association of drug resistance to co-trimoxazole $(80.2 \%$ vs. $47.1 \% ; \mathrm{P}=0.01)$, chloramphenicol $(73 \%$ vs. $52.9 \%$; $\mathrm{P}=0.05)$, and moxifloxacin $(71.4 \%$ vs. $41.2 \% ; \mathrm{P}=0.03)$. Meropenem and piperacillin-tazobactam had the lowest number of animal strains resistant to them, each at 10 (7.9\%), followed by $12(9.5 \%)$ strains resistant to cefoperazone-sulbactam, $16(12.7 \%)$ to imipenem, and $20(15.9 \%)$ to amikacin (Table 3).

For the human pathogens, there was a statistically significant association of antibiotic resistance, primarily to the cephalosporins: ceftriaxone $(64.7 \%$ vs. $22.2 \%$; $\mathrm{P}=0.01)$, cefuroxime $(58.8 \%$ vs. $23 \% ; \mathrm{P}=0.007)$, cefotaxime $(58.8 \%$ vs. $26.2 \% ; \mathrm{P}=0.01)$, ceftazidime $(58.8 \%$ vs. $19.8 \% ; \mathrm{P}<0.01)$, and cefixime $(52.9 \%$ vs. $25.4 \%$;

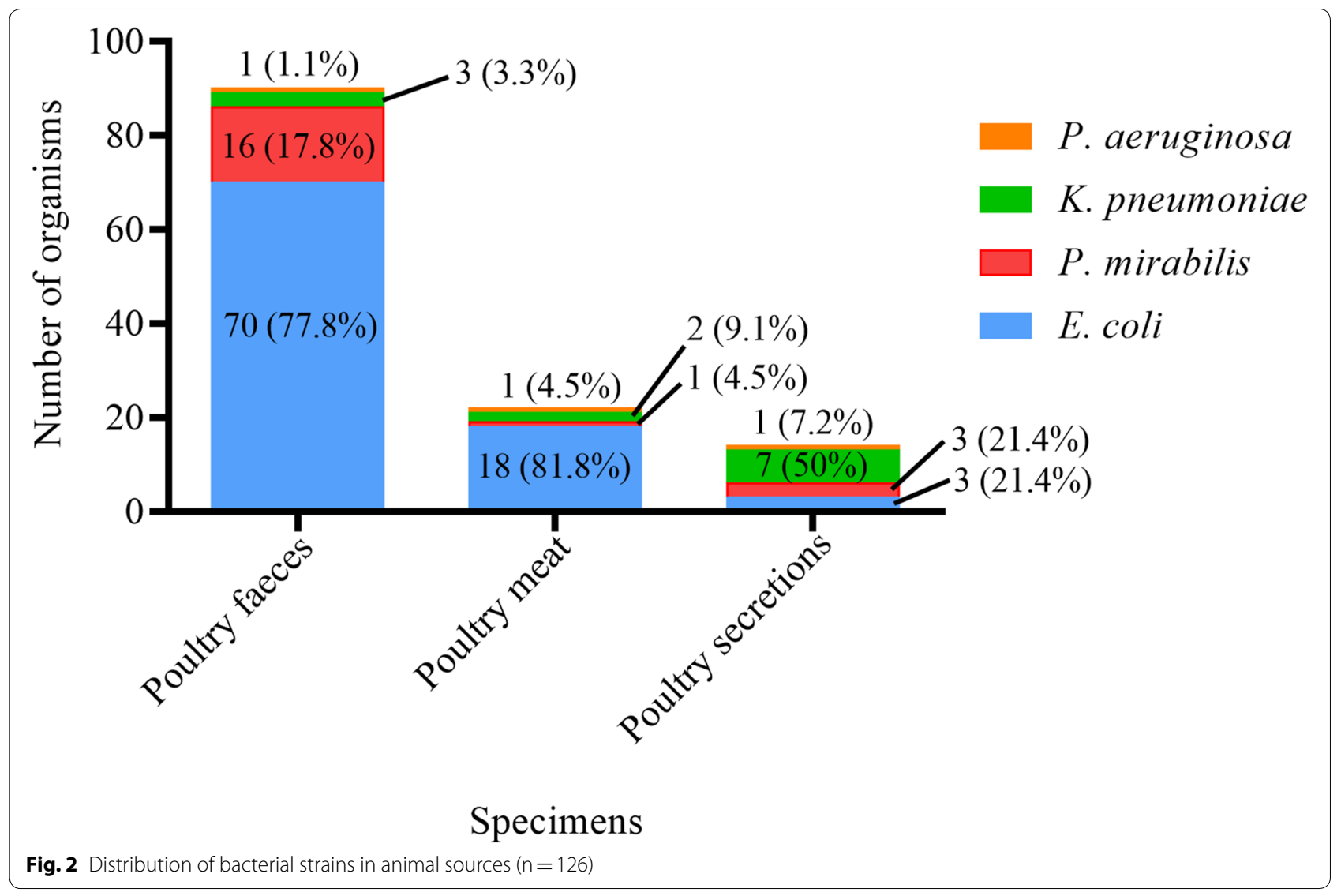


Table 3 Association of antibiotic resistance in animal and human bacterial strains $(n=143)$

\begin{tabular}{lllc}
\hline Antibiotics & $\begin{array}{l}\text { Animal isolates } \\
\mathbf{n = 1 2 6}(\%)\end{array}$ & $\begin{array}{l}\text { Human isolates } \\
\mathbf{n = 1 7}(\%)\end{array}$ & P-value \\
\hline Co-trimoxazole & $101(80.2)$ & $8(47.1)$ & 0.01 \\
Chloramphenicol & $92(73)$ & $9(52.9)$ & 0.05 \\
Moxifloxacin & $90(71.4)$ & $7(41.2)$ & 0.03 \\
Levofloxacin & $41(32.5)$ & $4(23.5)$ & 0.59 \\
Ciprofloxacin & $42(33.3)$ & $4(23.5)$ & 0.69 \\
Co-amoxiclav & $37(29.4)$ & $9(52.9)$ & 0.05 \\
Cefotaxime & $33(26.2)$ & $10(58.8)$ & 0.01 \\
Cefixime & $32(25.4)$ & $9(52.9)$ & 0.02 \\
Cefuroxime & $29(23)$ & $10(58.8)$ & 0.007 \\
Ceftriaxone & $28(22.2)$ & $11(64.7)$ & 0.01 \\
Ceftazidime & $25(19.8)$ & $10(58.8)$ & $<0.01$ \\
Amikacin & $20(15.9)$ & $4(23.5)$ & 0.73 \\
Imipenem & $16(12.7)$ & $5(29.4)$ & $<0.01$ \\
Cefoperazone-sulbactam & $12(9.5)$ & $4(23.5)$ & 0.22 \\
Piperacillin-tazobactam & $10(7.9)$ & $2(11.8)$ & 0.05 \\
Meropenem & $10(7.9)$ & $5(29.4)$ & 0.02 \\
\hline
\end{tabular}

$\mathrm{P}=0.02$ ). There was a statistically significant difference in resistance between the human isolates and the animal isolates to the beta-lactamase-resistant drugs, which include co-amoxiclav (52.9\% vs. 29.4\%; $\mathrm{P}=0.05$ ), meropenem $(29.4 \%$ vs. $7.9 \% ; \mathrm{P}=0.02)$, imipenem (29.4\% vs. $12.7 \%$; $<0.01)$, and piperacillin-tazobactam
(11.8\% vs. $7.9 \% ; \mathrm{P}=0.05)$. The lowest number of strains among the human pathogens resistant to a drug was 2 (11.8\%), which was for piperacillin-tazobactam, followed by 4 (23.5\%) each for cefoperazone-sulbactam, amikacin, ciprofloxacin, and levofloxacin (Table 3).

Escherichia coli and K. pneumoniae isolated from animal and human sources and $P$. aeruginosa isolated from animal sources showed more resistance to co-trimoxazole, chloramphenicol, and moxifloxacin than to the other drugs. All of the K. pneumoniae (human sources) and $P$. aeruginosa (animal sources) strains were also resistant to levofloxacin and ciprofloxacin. A. baumannii strains isolated from human sources showed resistance to all the antibacterial drugs except piperacillin-tazobactam. The detailed antimicrobial resistance profiles of the individual Col-R bacterial strains are presented in Table 4.

\section{MICs of colistin against Col-R bacterial strains}

The MICs of colistin against bacterial strains $(n=113)$ from human and animal sources showed MICs of 6, $8,12,24,32$, and $64 \mu \mathrm{g} / \mathrm{mL}$. Because of the intrinsic resistance to colistin, the MICs of all of the P. mirabilis strains were $>264 \mu \mathrm{g} / \mathrm{mL}$. The MIC distributions of colistin against human pathogens were $\mathrm{MIC}_{50}>6 \mu \mathrm{g} /$ $\mathrm{mL}$ and $\mathrm{MIC}_{90}>12 \mu \mathrm{g} / \mathrm{mL}$. The $\mathrm{MIC}_{50}$ and $\mathrm{MIC}_{90}$ values were $>12 \mu \mathrm{g} / \mathrm{mL}$ and $>32 \mu \mathrm{g} / \mathrm{mL}$, respectively, for the animal isolates (Fig. 3).

Table 4 Antimicrobial resistance profiles of individual colistin-resistant bacterial strains from animal and human sources

\begin{tabular}{|c|c|c|c|c|c|c|c|c|c|c|}
\hline \multirow[t]{2}{*}{ Antibiotics } & \multicolumn{2}{|l|}{ E. coli } & \multicolumn{2}{|c|}{ K. pneumoniae } & \multicolumn{2}{|c|}{ P. aeruginosa } & \multicolumn{2}{|c|}{ A. baumannii } & \multicolumn{2}{|c|}{ P. mirabilis } \\
\hline & $\begin{array}{l}\text { Animal } \\
(n=91)\end{array}$ & $\begin{array}{l}\text { Human } \\
(n=3)\end{array}$ & $\begin{array}{l}\text { Animal } \\
(n=12)\end{array}$ & $\begin{array}{l}\text { Human } \\
(n=1)\end{array}$ & $\begin{array}{l}\text { Animal } \\
(n=2)\end{array}$ & $\begin{array}{l}\text { Human } \\
(\mathrm{n}=0)\end{array}$ & $\begin{array}{l}\text { Animal } \\
(n=0)\end{array}$ & $\begin{array}{l}\text { Human } \\
(n=3)\end{array}$ & $\begin{array}{l}\text { Animal } \\
(n=20)\end{array}$ & $\begin{array}{l}\text { Human } \\
(n=10)\end{array}$ \\
\hline Co-trimoxazole & $64(70 \%)$ & $3(100 \%)$ & $5(42 \%)$ & $1(100 \%)$ & $2(100 \%)$ & - & - & $3(100 \%)$ & $8(40 \%)$ & $10(100 \%)$ \\
\hline Chloramphenicol & $64(70 \%)$ & $3(100 \%)$ & $5(42 \%)$ & $1(100 \%)$ & $2(100 \%)$ & - & - & $3(100 \%)$ & $8(40 \%)$ & $4(40 \%)$ \\
\hline Moxifloxacin & $59(65 \%)$ & $2(67 \%)$ & $5(42 \%)$ & $1(100 \%)$ & $2(100 \%)$ & - & - & $3(100 \%)$ & $3(15 \%)$ & $4(40 \%)$ \\
\hline Levofloxacin & $21(23 \%)$ & $1(33 \%)$ & $3(25 \%)$ & $1(100 \%)$ & $2(100 \%)$ & - & - & $2(75 \%)$ & $3(15 \%)$ & $1(10 \%)$ \\
\hline Ciprofloxacin & $38(42 \%)$ & $0(0 \%)$ & $2(17 \%)$ & $1(100 \%)$ & $2(100 \%)$ & - & - & $3(100 \%)$ & $5(25 \%)$ & $1(10 \%)$ \\
\hline Co-amoxiclav & $39(43 \%)$ & $2(67 \%)$ & $1(8 \%)$ & $1(100 \%)$ & $0(0 \%)$ & - & - & $3(100 \%)$ & $6(30 \%)$ & $1(10 \%)$ \\
\hline Cefotaxime & $35(38 \%)$ & $1(33 \%)$ & $1(8 \%)$ & $1(100 \%)$ & $0(0 \%)$ & - & - & $2(75 \%)$ & $3(15 \%)$ & $1(10 \%)$ \\
\hline Cefixime & $29(32 \%)$ & $2(67 \%)$ & $3(25 \%)$ & $1(100 \%)$ & $0(0 \%)$ & - & - & $3(100 \%)$ & $6(30 \%)$ & $3(30 \%)$ \\
\hline Cefuroxime & $27(30 \%)$ & $2(67 \%)$ & $0(0 \%)$ & $1(100 \%)$ & $0(0 \%)$ & - & - & $3(100 \%)$ & $7(35 \%)$ & $3(30 \%)$ \\
\hline Ceftriaxone & $27(30 \%)$ & $2(67 \%)$ & $1(8 \%)$ & $1(100 \%)$ & $0(0 \%)$ & - & - & $3(100 \%)$ & $7(35 \%)$ & $3(30 \%)$ \\
\hline Ceftazidime & $27(30 \%)$ & $1(33 \%)$ & $0(0 \%)$ & $1(100 \%)$ & $0(0 \%)$ & - & - & $3(100 \%)$ & $1(5 \%)$ & $3(30 \%)$ \\
\hline Amikacin & $16(18 \%)$ & $1(33 \%)$ & $3(25 \%)$ & $1(100 \%)$ & $0(0 \%)$ & - & - & $2(75 \%)$ & $2(10 \%)$ & $0(0 \%)$ \\
\hline Imipenem & $12(13 \%)$ & $1(33 \%)$ & $3(25 \%)$ & $1(100 \%)$ & $0(0 \%)$ & - & - & $1(33 \%)$ & $0(0 \%)$ & $2(20 \%)$ \\
\hline Cefoperazone-sulbactam & $7(8 \%)$ & $1(33 \%)$ & $2(17 \%)$ & $1(100 \%)$ & $1(50 \%)$ & - & - & $2(67 \%)$ & $2(10 \%)$ & $0(0 \%)$ \\
\hline Piperacillin-tazobactam & $9(10 \%)$ & $0(0 \%)$ & $0(0 \%)$ & $1(100 \%)$ & $0(0 \%)$ & - & - & $0(0 \%)$ & $2(10 \%)$ & $1(10 \%)$ \\
\hline Meropenem & $9(10 \%)$ & $1(33 \%)$ & $1(8 \%)$ & $1(100 \%)$ & $0(0 \%)$ & - & - & $3(100 \%)$ & $2(10 \%)$ & $0(0 \%)$ \\
\hline
\end{tabular}




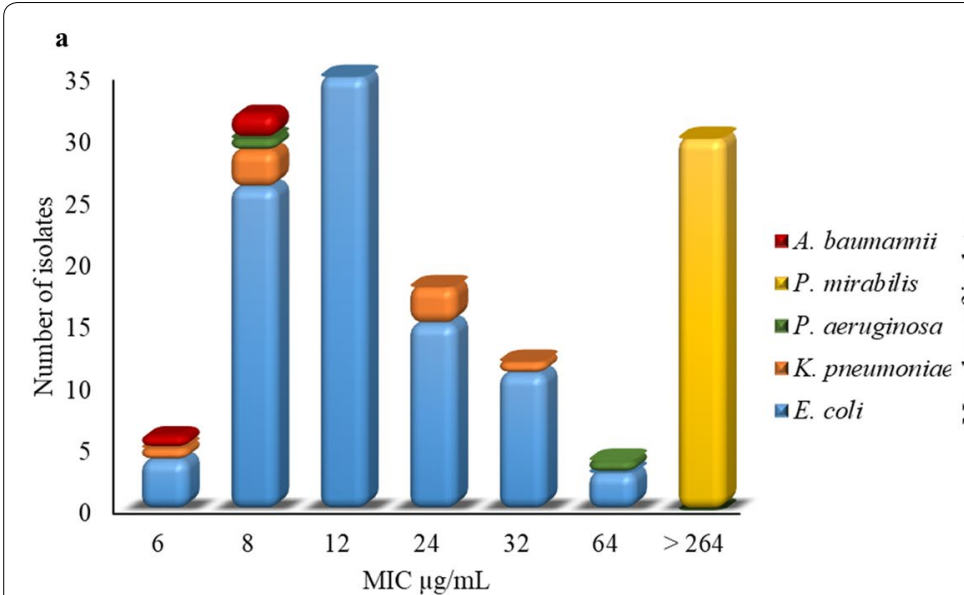

b

Fig. 3 MICs of colistin against colistin-resistant (Col-R) bacterial strains isolated from animal and human samples. a MICs of individual bacteria isolated from animal and human sources $(n=143)$. MIC values for all of the $P$. mirabilis strains were $>264 \mu \mathrm{g} / \mathrm{mL}$. $\mathbf{b}$ MIC ${ }_{50}$ and $\mathrm{MIC}_{90}$ of human and animal bacterial isolates $(n=113)$, excluding P. mirabilis because of its intrinsic Col- $R$

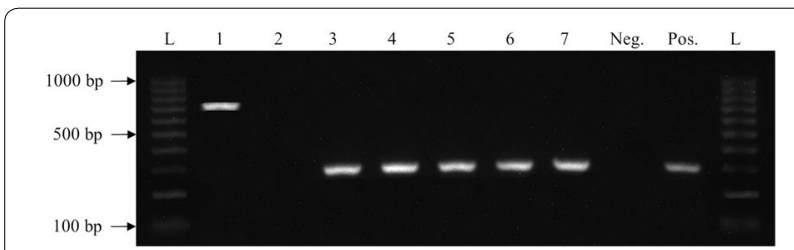

Fig. 4 Agarose gel electrophoresis of mar genes. Sample 1 shows the amplification of $m c r-2$, while specimens 3-7 show the amplified mcr-1 gene products. A 100 bp ladder (L) was included on both sides of the gel to estimate the gene sizes. Negative (Neg.) and positive (Pos.) controls were included in each gel

\section{Occurrence of mcr genes in isolated bacteria}

All of the Col-R gram-negative bacterial strains were analysed to determine the presence of $m c r-1, m c r-2, m c r-3$, $m c r-4$, and $m c r-5$. $m c r$ genes were detected in 110 (76.9\%) Col-R bacterial strains from animal and human sources, of which 108 (98.2) were $m c r-1$ and 2 (1.8\%) were $m c r-2$ (Fig. 4). For the animal pathogens, $m c r-1$ was found in 90 (83.3\%) E. coli strains, 12 (11.1\%) K. pneumoniae strains, and $1(0.9 \%)$ strain each of $P$. aeruginosa and $P$. mirabilis. For the human pathogens, $m c r-1$ was found in $3(2.8 \%)$ E. coli strains and $1(0.9 \%) K$. pneumoniae strain. Only $2(100 \%)$ strains of $P$. mirabilis isolated from the animal sources harboured $m c r-2$ (Table 5).

\section{Demographic and clinical data for the human isolates}

Analysis of the demographic and clinical data of the patients infected with Col- $R$ pathogens revealed that Col- $R$ strains were isolated from various clinical specimens from patients of different ages and genders. The $m c r-1$ gene was detected in $3 \mathrm{E}$. coli (urine specimen) strains and $1 \mathrm{~K}$. pneumoniae (blood specimen) strain, and none of the $m c r$ variants were identified in any other bacterial strain of human origin (Table 6).

\section{Discussion}

The global dissemination of ESBLs, AmpC, and carbapenemase-producing bacteria has narrowed the options for appropriate antibiotics to treat gram-negative

Table 5 Distribution of $m c r$ genes in human and animal bacterial strains $(n=110)$

\begin{tabular}{|c|c|c|c|c|}
\hline \multirow[t]{3}{*}{ Bacterial strains } & \multicolumn{2}{|c|}{$m c r-1(n=108 ; 98.2 \%)$} & \multicolumn{2}{|c|}{$m c r-2(n=2 ; 1.8 \%)$} \\
\hline & Animal n (\%) & Human n (\%) & Animal n (\%) & Human n (\%) \\
\hline & $104(96.3)$ & $4(3.7)$ & $2(100)$ & $0(0)$ \\
\hline E. coli & $90(83.3)$ & $3(2.8)$ & $0(0)$ & $0(0)$ \\
\hline K.pneumoniae & $12(11.1)$ & $1(0.9)$ & $0(0)$ & $0(0)$ \\
\hline P. aeruginosa & $1(0.9)$ & $0(0)$ & $0(0)$ & $0(0)$ \\
\hline P. mirabilis & $1(0.9)$ & $0(0)$ & $2(100)$ & $0(0)$ \\
\hline A. baumannii & $0(0)$ & $0(0)$ & $0(0)$ & $0(0)$ \\
\hline
\end{tabular}


Table 6 Demographic and clinical data of patients infected with colistin-resistant pathogens $(n=17)$

\begin{tabular}{|c|c|c|c|c|c|c|}
\hline Gender & Age (Years) & Ward & Organism isolated & Specimen & $\begin{array}{l}\text { Colistin MIC } \\
\mu \mathrm{g} / \mathrm{mL}\end{array}$ & morgene \\
\hline Male & 1 & Medical ICU & K.pneumoniae & Blood & 6 & $m c r-1$ \\
\hline Female & 38 & Outpatient department & E. coli & Urine & 6 & $m c r-1$ \\
\hline Female & 3 & Nephrology Ward & E. coli & Urine & 12 & $m c r-1$ \\
\hline Male & 67 & Cardiac ICU & E. coli & Urine & 6 & $m c r-1$ \\
\hline Female & 53 & Medical ICU & A. baumannii & Tracheal secretions & 8 & Not detected \\
\hline Male & 3 & Neurosurgery ICU & A. baumannii & Tracheal secretions & 8 & Not detected \\
\hline Female & 61 & Medical ICU & A. baumannii & Tracheal secretions & 6 & Not detected \\
\hline Female & 13 & Outpatient department & P. mirabilis & Urine & $\geq 264$ & Not detected \\
\hline Male & 68 & Medical Ward & P. mirabilis & Urine & $\geq 264$ & Not detected \\
\hline Male & 51 & Medical Ward & P. mirabilis & Stool & $\geq 264$ & Not detected \\
\hline Female & 8 & Nephrology Ward & P. mirabilis & Blood & $\geq 264$ & Not detected \\
\hline Male & 3 & Medical ICU & P. mirabilis & Tracheal secretions & $\geq 264$ & Not detected \\
\hline Male & 3 & Ortho Ward & P. mirabilis & Pus & $\geq 264$ & Not detected \\
\hline Male & 10 & General Surgery Ward & P. mirabilis & Pus & $\geq 264$ & Not detected \\
\hline Male & 73 & Cardiac ICU & P. mirabilis & Tracheal secretions & $\geq 264$ & Not detected \\
\hline Female & 6 & Neurosurgery Ward & P. mirabilis & CSF & $\geq 264$ & Not detected \\
\hline Female & 3 & Medical Ward & P. mirabilis & Urine & $\geq 264$ & Not detected \\
\hline
\end{tabular}

bacterial infections. The effectiveness of colistin in the treatment of XDR gram-negative bacterial infections is well known. In this era of antibacterial drug resistance, a new debate has started following the emergence of Col- $\mathrm{R}$ bacterial strains isolated from humans and animals. These strains can disseminate the $m c r$ genes to other susceptible bacterial strains [8]. Here, we found 143 GNR Col-R phenotypes, of which $88.1 \%$ were isolated from animals and $11.9 \%$ from human sources.

In our study, Col-R was predominantly observed in strains isolated from poultry faecal samples and in uropathogens isolated from hospitalized patients. Col-R is frequently observed in animal faecal strains, indicating the intestinal colonization of Col-R bacteria in these animals [20]. Col- $\mathrm{R}$ has been found and reported in different countries in samples from humans, animals, and the environment [5, 21-23]. The predominant Col-R strains found were E. coli $(72.2 \%)$ and P. mirabilis $(15.9 \%)$ from animal sources. E. coli (17.6\%) and P. mirabilis (58.8\%) were also the predominant strains from human sources, although the total number of Col-R strains was not high. These findings corroborate previous studies on Col-R $E$. coli, which reported rates of $8 \%$ from broiler chicken and $37.5 \%$ from pig rectal swabs $[9,24]$.

The treatment of infections caused by ESBL- and AmpC beta-lactamase-producing strains remains a major concern $[25,26]$. The emergence of NDM-1 during the past few years has made treating these infections challenging [27]. Polymyxin B and colistin have saved patients' lives and are considered a vital regimen for treating XDR bacterial infections [12]. Other studies have reported the use of colistin, aminoglycosides, co-trimoxazole, piperacillin-tazobactam, cefoperazone-sulbactam, and tigecycline to treat multidrug-resistant bacteria [18] Unfortunately, Col-R isolates have emerged worldwide because of the injudicious use of colistin, particularly in veterinary medicine [5].

Here, we analysed the antibacterial activity of aminoglycosides, cephalosporins, fluoroquinolones, carbapenems, beta-lactam, and other combinations against Col-R phenotypes. We found $\mathrm{MIC}_{90}$ values $>12 \mu \mathrm{g} / \mathrm{mL}$ and $>32 \mu \mathrm{g} / \mathrm{mL}$ for the clinical and animal isolates, respectively. It is important to accurately determine the MICs of colistin and the detection of $\mathrm{mcr}$ genes provides valuable information to better understand the mechanism of resistance in borderline or resistant cases [19]. In our study, the animal strains were significantly resistant to co-trimoxazole, chloramphenicol, and moxifloxacin, which is consistent with the findings of a Thai study [28]. Interestingly, we noticed lower resistance to carbapenems, piperacillin-tazobactam, cefoperazone-sulbactam, and amikacin. These antibiotics are currently used to combat bacterial infections. Nevertheless, this raises the question of what alternatives would be left if these organisms were found to harbour ESBL, AmpC, NDM-1, and Col-R together. We can speculate that this could lead us into the post-antibiotic era, where we would have no remaining options to treat XDR strains.

The prevalence of the $m c r-1$ gene has been reported in different animals from 28 countries [29]. The $m$ mor gene 
is more frequently isolated from animal strains than from human bacterial strains [5]. We found that $98.2 \%$ of our bacterial strains from both the animal and human sources contained $m c r-1$. Two cases $(1.8 \%)$ of $m c r-2$ were found, both in $P$. mirabilis isolated from animal sources, while none of the other $m c r$ variants were found in our study. The presence of plasmid-mediated $\mathrm{mor}$ resistance has been reported in different regions around the world [5, 21-23]. A study in Argentina reported 149 (49\%) cases of Col-R in E. coli isolated from poultry, and all of them harboured the $m c r-1$ gene [30]. The coexistence of $m c r-1$ genes from animal, clinical, and environmental sources has also been reported in several Asian countries [31]. The $m c r-1$ gene is primarily found in E. coli and $K$. pneumoniae of human origin, which is in line with our study. The plasmid-mediated Col-R possibly developed in animals and was ultimately transmitted to humans $[5,32$, 33].

The four human isolates which harboured $m c r-1$ in our study were isolated from one septic ICU patient and three patients with urinary tract infections from different wards. We did not find any history of travel or previous use of colistin for these patients. The exact source of $m c r-1$ could also not be established in an Egyptian and a Polish study; however, some evidence implicated the community exposure of the patients $[34,35]$. The detection of $m c r-1$ and $m c r-2$ in P. mirabilis in our study may be the first report of $\mathrm{mcr}$ genes identified in an intrinsically Col-R organism. This finding may not be significant as far as antibacterial resistance is concerned, and $\mathrm{mcr}$ genes are probably not usually searched for in an intrinsically resistant organism. However, this finding indicates the potential danger of the dissemination of $\mathrm{mcr}$-mediated drug resistance to susceptible bacterial strains.

This study had few limitations. One limitation of our study is that we were not able to perform the broth microdilution test on all Col-R strains because of financial and time limitations. Second, we could not establish a definite route for acquiring $\mathrm{mcr}$ genes in clinical settings. Moreover, in the statistical comparison of drug resistance, having fewer bacterial isolates in one category could have affected the statistical analysis.

\section{Conclusions}

The plasmid-mediated Col- $\mathrm{R}$ in GNRs among poultry is a significant emerging problem. The transfer of $\mathrm{mcr}$ genes to human bacterial strains represents a danger for patients with XDR infections. The use of colistin to promote growth in animals and increase agriculture production and its indiscriminate use in clinical settings are potential reasons for the dissemination of plasmidmediated Col-R. We identified considerable animal reservoirs harbouring $\mathrm{mcr}$ genes that could be transferred to environmental and human strains, leading to acquired Col-R. A crucial finding of this study was the detection of the $m c r-2$ gene in intrinsically Col-R $P$. mirabilis, as it could lead to the uncontrolled spread of $\mathrm{mor}$ genes among animals and human microbiota. The rationale for the use of colistin and its availability for livestock use without a prescription should be critically reviewed to decrease the dissemination of Col-R bacteria in humans and animals.

\section{Abbreviations \\ Col-R: Colistin resistance; mcr: Mobile colistin resistance; MIC: Minimum inhibi- tory concentration; PCR: Polymerase chain reaction; QC: Quality control; XDR: Extensively drug-resistant; ESBLs: Extended-spectrum beta-lactamases; GNR: Gram-negative rods.}

\section{Acknowledgements}

We thank the Higher Education Commission of Pakistan, University of Health Sciences Lahore, University of Veterinary and Animal Sciences Lahore, and The Children's Hospital, Lahore Pakistan, for their support of this study.

\section{Authors' contributions}

HJ conceived the idea. HJ, SS, and SJ designed the study, collected the data, and performed the experiments. AZ and HE collected the clinical specimens and performed the experiments. AG and ABS collected the animal samples and performed the experiments. HJ, HE and KJ performed the statistical analysis and wrote the initial manuscript. All authors read and approved the final manuscript.

\section{Funding}

The study was supported by the Higher Education Commission of Pakistan (Project No. NRPU 8557).

\section{Availability of data and materials}

All the data supporting the findings are presented in the manuscript.

\section{Ethics approval and consent to participate}

The University of Health Sciences and the Children's Hospital and Institute of Child Health Lahore, Pakistan, provided ethics approval for the study. The study did not include any interventional human or animal procedures.

Consent for publication

Not applicable.

\section{Competing interests}

The authors declare that they have no competing interests.

\section{Author details}

${ }^{1}$ Department of Microbiology, University of Health Sciences, Lahore, Pakistan. ${ }^{2}$ Department of Microbiology, The Children's Hospital \& The Institute of Child Health, Lahore, Pakistan. ${ }^{3}$ University Diagnostic Laboratory, University of Veterinary and Animal Sciences, Lahore, Pakistan. ${ }^{4}$ Department of Clinical Laboratory Sciences, College of Applied Medical Sciences, Jouf University, Al Jouf, Saudi Arabia. ${ }^{5}$ Department of Immunology, University of Health Sciences, Khayaban-e-Jamia Punjab, 54600 Lahore, Pakistan.

Received: 18 July 2020 Accepted: 4 November 2020

Published online: 20 November 2020

References

1. Shad A. MCR-1 colistin resistance in Escherichia coli wild life: a continental mini-review. J Drug Metab Toxicol. 2018;9:243.

2. Coetzee J, Corcoran C, Prentice E, Moodley M, Mendelson M, Poirel $L$, et al. Emergence of plasmid-mediated colistin resistance (MCR-1) 
among Escherichia coli isolated from South African patients. S Afr Med J. 2016;106:35-6.

3. Liu Y, Liu JH. Monitoring colistin resistance in food animals. An urgent threat. Expert Rev Anti Infect Ther. 2018;16:443-6.

4. Dandachi I, Chabou S, Daoud Z, Rolain JM. Prevalence and emergence of extended-spectrum cephalosporin-, carbapenem- and colistin-resistant gram negative bacteria of animal origin in the Mediterranean Basin. Front Microbiol. 2018;9:2299.

5. Liu YY, Wang Y, Walsh TR, Yi LX, Zhang R, Spencer J, et al. Emergence of plasmid-mediated colistin resistance mechanism MCR-1 in animals and human beings in China: a microbiological and molecular biological study. Lancet Infect Dis. 2016;16:161-8.

6. Luo $Q$, Wang Y, Xiao Y. Prevalence and transmission of mobilized colistin resistance $(\mathrm{mcr})$ gene in bacteria common to animals and humans. Biosaf Health. 2020;2020:71-8.

7. Carretto E, Brovarone F, Nardini P, Russello G, Barbarini D, Pongolini S, et al. Detection of mcr-4 positive Salmonella enterica serovar Typhimurium in clinical isolates of human origin, Italy, October to November 2016. Euro Surveill. 2018;23:17-00821.

8. Grondahl-Yli-Hannuksela K, Lonnqvist E, Kallonen T, Lindholm L, Jalava J, Rantakokko-Jalava K, et al. The first human report of mobile colistin resistance gene, mcr-1, in Finland. APMIS. 2018;126:413-17.

9. LV J, Mohsin M, Lei S, Srinivas S, Wiqar RT, Lin J, et al. Discovery of a mcr1-bearing plasmid in commensal colistin-resistant Escherichia coli from healthy broilers in Faisalabad, Pakistan. Virulence. 2018;9:994-99.

10. Moosavian M, Emam N. The first report of emerging mobilized colistinresistance ( $\mathrm{mcr}$ ) genes and ERIC-PCR typing in Escherichia coli and Klebsiella pneumoniae clinical isolates in southwest Iran. Infect Drug Resist. 2019;12:1001-10

11. Zhang J, Chen L, Wang J, Butaye P, Huang K, Qiu H, et al. Molecular detection of colistin resistance genes (mcr-1 to $\mathrm{mcr}-5$ ) in human vaginal swabs. BMC Res Notes. 2018;11:143.

12. Olaitan AO, Chabou S, Okdah L, Morand S, Rolain JM. Dissemination of the mcr-1 colistin resistance gene. Lancet Infect Dis. 2016;16:147.

13. Roer L, Hansen F, Stegger M, Sönksen UW, Hasman H, Hammerum AM. Novel mcr-3 variant, encoding mobile colistin resistance, in an ST131 Escherichia coli isolate from bloodstream infection, Denmark, 2014. Euro Surveill. 2017;22:22846.

14. Chen K, Chan EW, Xie M, Ye L, Dong N, Chen S. Widespread distribution of mcr-1-bearing bacteria in the ecosystem, 2015 to 2016. Euro Surveill. 2017;22:17-00206.

15. Javed H, Ejaz H, Zafar A, Rathore AW. Metallo-beta-lactamase producing Escherichia coli and Klebsiella pneumoniae: a rising threat for hospitalized children. J Pak Med Assoc. 2016;66:1068-72.

16. Clinical and Laboratory Standard Institute (CLSI). Performance Standards for Antimicrobial Susceptibility Testing. 27th edi. CLSI Supplement M100 Wayne: Clinical and Laboratory Standard Institute; 2017.

17. Clinical and Laboratory Standard Institute (CLSI). Performance Standards for Antimicrobial Susceptibility Testing. 28th edi. CLSI Supplement M100. Wayne: Clinical and Laboratory Standard Institute; 2018.

18. Ejaz H, Alzahrani B, Hamad MFS, Abosalif KOA, Junaid K, Abdalla AE, et al. Molecular analysis of the antibiotic resistant NDM-1 gene in clinical isolates of Enterobacteriaceae. Clin Lab. 2020;66:409-17.

19. Rebelo AR, Bortolaia V, Kjeldgaard JS, Pedersen SK, Leekitcharoenphon P, Hansen IM, et al. Multiplex PCR for detection of plasmid-mediated colistin resistance determinants, mcr-1, mcr-2, mcr-3, mcr-4 and mcr-5 for surveillance purposes. Euro Surveill. 2018;23:17-00672.
20. El Garch F, de Jong A, Bertrand X, Hocquet D, Sauget M. mcr-1-like detection in commensal Escherichia coli and Salmonella spp. from foodproducing animals at slaughter in Europe. Vet Microbiol. 2018;213:42-6.

21. Mulvey MR, Mataseje LF, Robertson J, Nash JH, Boerlin P, Toye B, et al. Dissemination of the mcr-1 colistin resistance gene. Lancet Infect Dis. 2016;16:289-90.

22. Shen Z, Wang Y, Shen Y, Shen J, Wu C. Early emergence of mcr-1 in Escherichia coli from food-producing animals. Lancet Infect Dis. 2016;16:293.

23. Xavier BB, Lammens C, Ruhal R, Kumar-Singh S, Butaye P, Goossens $H$, et al. Identification of a novel plasmid-mediated colistin-resistance gene, mcr-2, in Escherichia coli, Belgium, June 2016. Euro Surveill. 2016;21:1-6.

24. Stoesser N, Mathers AJ, Moore CE, Day NP, Crook DW. Colistin resistance gene mcr-1 and pHNSHP45 plasmid in human isolates of Escherichia coli and Klebsiella pneumoniae. Lancet Infect Dis. 2016;16:285-6.

25. Ejaz H, Wang N, Wilksch JJ, Page AJ, Cao H, Gujaran S, et al. Phylogenetic Analysis of Klebsiella pneumoniae from Hospitalized Children, Pakistan. Emerg Infect Dis. 2017;23:1872-75.

26. Younas S, Ejaz H, Zafar A, Ejaz A, Saleem R, Javed H. AmpC beta-lactamases in Klebsiella pneumoniae: An emerging threat to the paediatric patients. J Pak Med Assoc. 2018;68:893-97.

27. Heinz E, Ejaz H, Bartholdson Scott J, Wang N, Gujaran S, Pickard D, et al. Resistance mechanisms and population structure of highly drug resistant Klebsiella in Pakistan during the introduction of the carbapenemase NDM-1. Sci Rep. 2019;9:2392.

28. Strom G, Halje M, Karlsson D, Jiwakanon J, Pringle M, Fernstrom LL, et al. Antimicrobial use and antimicrobial susceptibility in Escherichia coli on small- and medium-scale pig farms in north-eastern Thailand. Antimicrob Resist Infect Control. 2017;6:75.

29. Al-Tawfiq JA, Laxminarayan R, Mendelson M. How should we respond to the emergence of plasmid-mediated colistin resistance in humans and animals? Int J Infect Dis. 2017;54:77-84.

30. Dominguez JE, Faccone D, Tijet N, Gomez S, Corso A, FernándezMiyakawa ME, et al. Characterization of Escherichia coli carrying mcr1-plasmids recovered from food animals from Argentina. Front Cell Infect Microbiol. 2019;9:41.

31. Skov RL, Monnet DL. Plasmid-mediated colistin resistance (mcr-1 gene): three months later, the story unfolds. Euro Surveill. 2016;21:30155.

32. Pishnian Z, Haeili M, Feizi A. Prevalence and molecular determinants of colistin resistance among commensal Enterobacteriaceae isolated from poultry in northwest of Iran. Gut Pathog. 2019;11:2.

33. Johura FT, Tasnim J, Barman I, Biswas SR, Jubyda FT, Sultana M, et al. Colistin-resistant Escherichia coli carrying mcr-1 in food, water, hand rinse, and healthy human gut in Bangladesh. Gut Pathog. 2020;12:5.

34. Elnahriry SS, Khalifa HO, Soliman AM, Ahmed AM, Hussein AM, Shimamoto T, et al. Emergence of plasmid-mediated colistin resistance Gene mcr-1 in a clinical Escherichia coli isolate from Egypt. Antimicrob Agents Chemother. 2016;60:3249-50.

35. Izdebski R, Baraniak A, Bojarska K, Urbanowicz P, Fiett J, PomorskaWesołowska M, et al. Mobile MCR-1-associated resistance to colistin in Poland. J Antimicrob Chemother. 2016;71:2331-3.

\section{Publisher's Note}

Springer Nature remains neutral with regard to jurisdictional claims in published maps and institutional affiliations. 